\title{
Computed Tomography During Experimental Balloon Dilatation For Calcific Aortic Stenosis. A Look into the Mechanism of Valvuloplasty
}

\author{
CARLO DI MARIO, M.D., LEONARD C.P. VAN VEEN, M.D.,* LEEN DE BAAT, M.Sc.,* \\ CATHARINA E. ESSED, M.D.,** KEVIN J. BEATT, M.R.C.P., OLIVER LEBORGNE M.D., \\ and PATRICK W. SERRUYS, MD, PH.D.
}

From Thoraxcenter (Cardiac Catheterization Laboratory), *Experimental Radiology, and **Pathology Department 1 , Erasmus University, Rotterdam, The Netherlands

Thin-slice contiguous computed tomographic scanning was performed in four postmortem hearts with calcific aortic valve stenosis (mean weight: $583 \pm 78 \mathrm{~g}$; mean age: $65 \pm 10$ years) before, during, and after balloon valvuloplasty. Balloons of increasing diameter (15-19 $\mathrm{mm}$ single balloons, and $3 \times 12-\mathrm{mm}$ trefoil-shaped balloon) were positioned across the aortic valve and manually inflated to pressures of 3 to 4 atmospheres. During inflation of the $3 \times 12-\mathrm{mm}$ balloon a larger residual orifice, potentially free for blood passage, was observed in the two cases with bicuspid valves and in one case with a fused tricuspid valve, while the reverse was noted in one case with a tricuspid valve without fusion. In most cases valvular orifice enlargement only occurred with larger diameter balloons. After valvuloplasty aortic valve area increased from 0.72 (range $0.20-0.95$ ) $\mathrm{cm}^{2}$ to 2.36 (range $0.95-3.14) \mathrm{cm}^{2}$. The smallest orifice en-

\section{Introduction}

Aortic balloon valvuloplasty was originally introduced for young patients with congenital aortic

Address for reprints: Patrick W. Serruys, M.D., Ph.D., Cardiac Catheterization Laboratory, Thoraxcenter, Erasmus University, P.0. Box 1738, 3000 DR Rotterdam, The Netherlands.

Present address of Dr. Carlo Di Mario is the Div. Cardiologica, Cittadella (PD), Italy.

Dr. Kevin $\mathbf{J}$ Beatt is the recipient of the Joint Fellowship from the British and the Netherlands Heart Foundations.

Submitted for publication April 14, 1988; accepted May 17, 1988. largement after dilatation occurred in case 1 . where valvular calcified deposits had the largest volume and the highest computed tomographic attenuation value. In each patient macroscopic changes (fracture of nodular calcifications, commissural splitting, tearing of the central raphe) were noted. No calcium dislodgement or aortic ring damage was observed. In autopsy specimens computed tomography provided accurate evaluation of aortic valve morphology, extent of valve calcification, balloon-leaflet relationship during inflation, and effects of the dilatation on valve leaflets and commissures. Advances in computed tomographic cardiovascular imaging may achieve similar results in the clinical setting, and allow a more rational, individualized approach to the valvuloplasty procedure. (J Interven Cardiol 1988:1:2)

stenosis, ${ }^{1}$ and later on applied to cases of severe, calcified aortic stenosis in elderly patients. ${ }^{2} \mathrm{En}$ couraging results have recently been reported in many series of elderly patients. ${ }^{3-9}$ Cribier et al. ${ }^{10}$ obtained an increase in aortic valve area from 0.49 \pm 0.17 to $0.93 \pm 0.36 \mathrm{~cm}^{2}$ in 92 patients, resulting in a "dramatic in-hospital clinical improvement" in most patients.

However, the immediate result of balloon valvuloplasty is largely unpredictable, with the incidence of nonresponding or poorly responding patients (aortic valve area still $<0.7 \mathrm{~cm}^{2}$ at the end of the procedure) ranging from $18.7 \%^{5}$ to $38.2 \% .^{9} \mathrm{Ra}-$ tional selection of patients more amenable to balloon dilatation requires a complete characteriza- 
DI MARIO, ET AL.
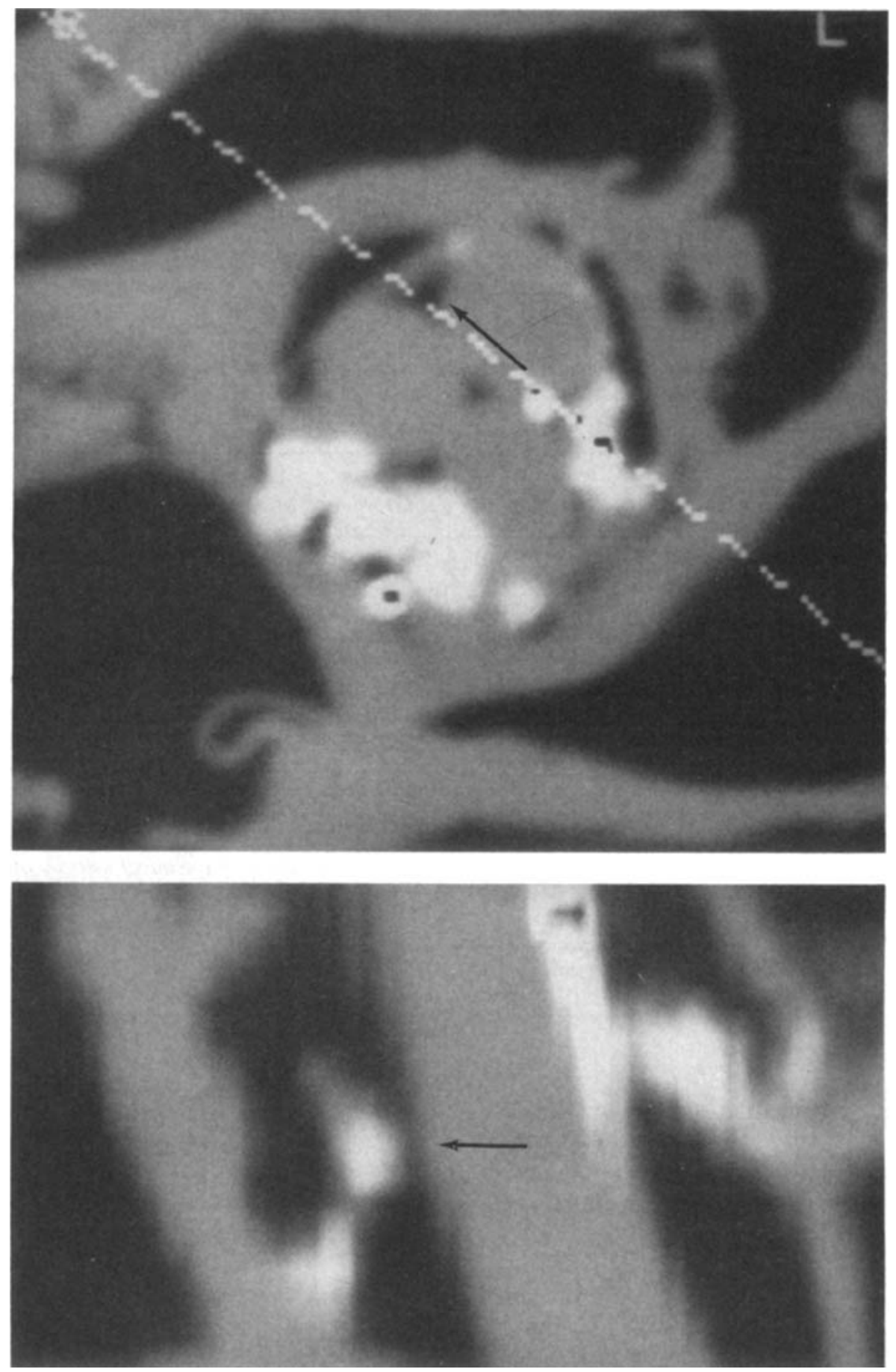

Figure 1. Example of sagittal reconstruction of the aortic valve region (Philips Stand Alone Viewing System $^{R}$, Philips Medical Services, Best, The Netherlands). The upper picture shows an axial scan (enlargement factor: $2 \times$ ) of a heavily calcified aortic valve (case 1 ) during inflation of a $3 \times 12-\mathrm{mm}$ trefoil balloon. The dotted line indicates the level choosen for the reconstruction shown in the lower picture, where a central balloon displacing the calcific right and left coronary cusps is observed. The reconstruction demonstrates that the apparently free triangular space between balloon and right leaflet observed in the axial scan (upper picture, arrow), is in fact almost completely occupied by 


\section{COMPUTED TOMOGRAPHY DURING AORTIC VALVULOPLASTY}

tion of the individual valve morphology ${ }^{11}$ and the knowledge of the underlying mechanisms of valvuloplasty.

McKay et al. ${ }^{12,13}$ have performed balloon valvuloplasty in post-mortem hearts and in patients intraoperatively. Successful valvuloplasty was related to gross fracture of nodular calcification, commissural separation, and/or stretching of rigid valve leaflets. However, only a visual evaluation was used with no attempt at quantification. Vahanian et al. ${ }^{14}$ recently reported the results of experimental valvuloplasty in 22 autopsy specimens, analysed by low energy $x$-ray and direct visual evaluation. According to these authors the observed increase in aortic valve area (from 0.68 \pm 0.34 to $2.72 \pm 0.78 \mathrm{~cm}^{2}$ ) was related to "an improvement in cusp motion due to calcium redistribution."

Thin-slice contiguous axial computed tomography avoids superimposition of structures and provides vastly superior density resolution compared to conventional $x$-ray techniques. Therefore, we used computed tomographic scanning in order to obtain detailed quantitative information on the intravalvular calcium distribution before and after valvuloplasty, and to evaluate the effects of balloons of various size and shape during dilatation.

\section{Methods}

Material. We selected four hearts with calcific, stenotic aortic valves and intact aortic rings from our collection of autopsy specimens (Pathology Department 1, Erasmus University). The specimens were originally preserved in 10\% formalin solution but were kept in water for 30 days before valvuloplasty. A premortem cardiac catheterization showed a mean systolic transaortic gradient and aortic valve area of $77 \mathrm{mmHg}$ and $0.72 \mathrm{~cm}^{2}$ in case 4 , and of $70 \mathrm{mmHg}$ and $0.62 \mathrm{~cm}^{2}$ in case 2 . In this latter patient mild aortic insufficiency, moderate combined mitral disease and subocclusive stenoses of left anterior descending and left circumflex arteries were also observed. Patient 1 died suddenly. Patient 2 died as a consequence of a large anterior myocardial infarction. Irreversible cardiogenic shock developed in patient 3 as a result of a posterior myocardial infarction. Patient 4 , while awaiting surgical correction, developed acute pulmonary edema.

The hearts weighed $538-700 \mathrm{~g}$ (average $583 \mathrm{~g}$ ). The average thickness of the left ventricular wall was $19.5 \pm 1.9 \mathrm{~mm}$.

Extensive, nodular calcifications of the valve cusps projecting into the valve sinuses without conmissural fusion were observed in case 1 . The coexisting mitral valve disease and the tight, heavily calcified commissural fusion between noncoronary and right coronary aortic cusps, were in accordance with a rheumatic etiology in case 2 . Vegetative, nodular calcifications on the aortic aspects of the cusps were also observed. In case 3 the aortic valve was congenitally bicuspid. The larger anterior coronary cusp was divided by a central calcific raphe, extending across the floor of the aortic sinus from aorta to the free edge. The valve had no commissural fusion, and moderate nodular calcification.

In case 4 the valve was also congenitally bicuspid, but with an almost symmetric configuration, a moderate bilateral commissural fusion, and diffuse calcification, confined to the valve leaflets. In the anterior cusp, a calcified central raphe was observed. Cylindrical calipers of increasing diameter (range: $3-30 \mathrm{~mm}$ ) were used to assess the aortic valve orifice area, while the aortic ring diameter was measured directly.

Computed Tomographic Scan Procedure. All specimens were examined on a Tomoscan 350 clinical unit. ${ }^{\mathbf{R}}$ (Philips, Phillips Medical Systems, Best, The Netherlands) The hearts were positioned centrally in the scanner aperture (table height: upper), as shown in Figure 1. Three radiopaque markers were sutured to the aortic wall at the leaflet level and used as reference points in the scanning and reconstruction procedures. Axial scan series, covering the entire aortic valve region, were performed with contiguous scans of $1.5-\mathrm{mm}$ thickness.

The following technical factors were used: 120 $\mathrm{kVp}, 9.6 \mathrm{~s}, 200 \mathrm{~mA}$, field of view: 140 . Reconstruction algorithms for bone imaging were used.

nodular valve calcification (lower picture, arrow) when all the scanned planes are reconstructed and analyzed. $L=$ left; $R=$ right. 


\section{MARIO, ET AL.}

In order to obtain accurate and reproducible values in the assessment of the amount of calcific tissue, we corrrelated the values of the valves with the values of a reference phantom containing standard concentrations of $\mathrm{K}_{2} \mathrm{HPO}_{4}{ }^{15,16}$

Off-line evaluation was performed on a Philips Stand Alone Viewing System, ${ }^{\mathbf{R}}$ enabling sagittal reconstruction (Fig. 1), contour detection, and calculation of volumes and mean computed tomographic attenuation values of the region of interest. In order to discriminate between soft heart tissue (mean computed tomographic value: $50 \pm 15$ Hounsfield units) and heavy valvular calcification, the analysis of valvular calcium deposits was performed with a window width and window level of 200/200 Hounsfield units. In case 1, where the largest volume and the highest density of the valvular calcific deposits were observed before dilatation, the assessment of the volumes and computed tomographic attenuation values were repeated during and after each dilatation. In all specimens the region of interest contour mode was used to determine the residual orifice area during each inflation. Evaluation of all the axial scans was used to assess the minimal free space between leaflets and balloon.

Valvuloplasty Procedure. Postmortem aortic valvuloplasty was performed with balloons of increasing diameter, passed retrogradely from the aorta into the left ventricle. First a $15-\mathrm{mm}$ balloon (area: $1.8 \mathrm{~cm}^{2}$ ) was manually inflated across the aortic valve with a pressure of three atmospheres. Thereafter, a second and third dilatation were performed with a $19 \mathrm{~mm}$ (area: $2.8 \mathrm{~cm}^{2}$ ) and a $3 \times 12$ $\mathrm{mm}$ (equivalent area: $3.8 \mathrm{~cm}^{2}$ Schneider Medin- tag, Zurich, Switzerland) balloon catheter, both inflated to a pressure of four atmospheres.

Visual evaluation, photographs, measurement of the aortic valve orifice by cylindrical calipers, and axial computed tomographic scans were obtained at the beginning of the procedure and repeated after each dilatation. Computed tomographic scanning was also performed during the inflation of the balloons.

At the end of the procedure the valve was excised and histologic evaluation was performed after decalcification.

\section{Results}

Table 1 summarizes the macroscopic aspect of the four valves in addition to the aortic valve areas $\left(\mathrm{cm}^{2}\right)$ at the beginning of the procedure and after dilatation. Volume and mean computed tomographic attenuation value of the calcific deposits are also tabulated. The largest volume and the highest computed tomographic attenuation value were observed in case 1 .

First Dilatation: 15-mm balloon. In none of the specimens did the inflated $15-\mathrm{mm}$ balloon occupy a central position in the aortic orifice, as shown in Figure 2. In case 1 the balloon was displaced towards the less calcified left aortic cusp, in case 2 to the opposite side of the fused commissure between right and noncoronary cusps, and in case 3 and, to a lesser extent, in case 4 the rigidity of the calcific central raphe displaced the balloon posteriorly. Therefore, the stretching induced by the balloon was greater on the less calcified aortic valve leaflets

Table 1. Clinical Data, Computed Tomographic Evaluation of Valve Calcium Deposits, Ring Diameter, and Aortic Valve Area Before and After Dilatation with 15,19 , and $3 \times 12 \mathrm{~mm}$ Balloons

\begin{tabular}{|c|c|c|c|c|c|c|c|c|c|c|}
\hline \multirow[b]{2}{*}{ Case } & \multirow[b]{2}{*}{ Sex } & \multirow[b]{2}{*}{$\begin{array}{l}\text { Age } \\
\text { Yrs }\end{array}$} & \multirow[b]{2}{*}{$\begin{array}{l}\text { No } \\
\text { Cusps }\end{array}$} & \multicolumn{2}{|c|}{$\begin{array}{l}\text { Valve Calcium } \\
\text { Deposit }\end{array}$} & \multirow{2}{*}{$\begin{array}{l}\text { Valve Ring } \\
\text { Diameter } \\
(\mathrm{mm})\end{array}$} & \multirow[b]{2}{*}{$\begin{array}{l}\text { Basal } \\
\text { A.V.A. }\end{array}$} & \multirow[b]{2}{*}{$\begin{array}{l}\text { After } 15 \mathrm{~mm} \\
\text { A.V.A. }\end{array}$} & \multirow[b]{2}{*}{$\begin{array}{l}\text { After } 19 \mathrm{~mm} \\
\text { A.V.A. }\end{array}$} & \multirow[b]{2}{*}{$\begin{array}{c}\text { After } 3 \times 12 \mathrm{~mm} \\
\text { A.V.A. }\end{array}$} \\
\hline & & & & $\begin{array}{l}\text { Volume } \\
\left(\mathrm{cm}^{3}\right)\end{array}$ & $\begin{array}{l}\text { CT Value } \\
\text { (HU) }\end{array}$ & & & & & \\
\hline 1 & $F$ & 67 & 3 & 1.21 & 948 & 24 & 0.20 & 0.28 & 0.50 & 0.95 \\
\hline 2 & M & 71 & 3 & 0.29 & 132 & 24 & 0.78 & 1.76 & 2.26 & 3.14 \\
\hline 3 & $\mathbf{M}$ & 73 & 2 & 0.19 & 281 & 22 & 0.95 & 0.95 & 1.76 & 2.83 \\
\hline 4 & $\mathbf{F}$ & 50 & 2 & 0.17 & 121 & 20 & 0.95 & 0.95 & 1.76 & 2.54 \\
\hline $\begin{array}{l}\text { Mean } \\
\pm \text { SD }\end{array}$ & & $\begin{array}{r}65 \\
\pm 10\end{array}$ & & $\begin{array}{r}0.46 \\
\pm 0.50\end{array}$ & $\begin{array}{r}370 \\
\pm 392\end{array}$ & $\begin{array}{r}22.5 \\
\pm 1.9\end{array}$ & $\begin{array}{r}0.72 \\
\pm 0.36\end{array}$ & $\begin{array}{r}0.98 \\
\pm 0.60\end{array}$ & $\begin{array}{r}1.57 \\
\pm 0.75\end{array}$ & $\begin{array}{r}2.36 \\
\pm 0.97\end{array}$ \\
\hline
\end{tabular}

A.V.A.: aortic valve area $\left(\mathrm{cm}^{2}\right)$; CT value: computed tomographic attenuation value; F: female; HU: Hounsfield Units; M: male. 


\section{COMPUTED TOMOGRAPHY DURING AORTIC VALVULOPLASTY}
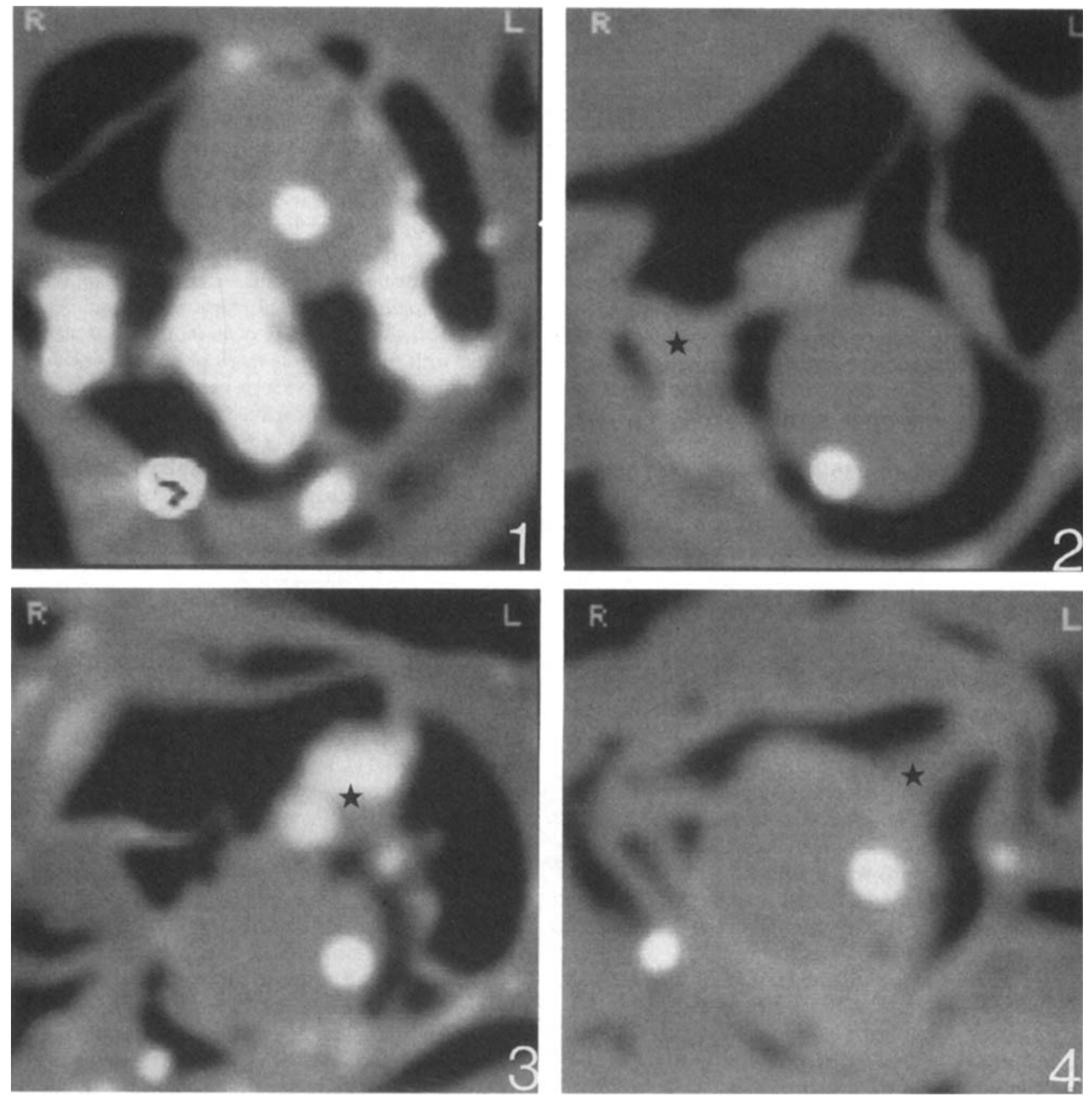

Figure 2. Axial scans of the four specimens at the level of the aortic valve orifice during inflation of a 15-mm balloon (enlargement factor: $4 \times$ ). The density is decreasing from the white areas (heavy calcium deposits, catheters, radiopaque markers), to the grey (heart and valve soft tissue), and the black areas (air). The balloon is displaced towards the less calcified leaflet in case 1, to the opposite side of the commissural fusion between right and noncoronary cusp $\left(^{*}\right)$ in case 2 , and towards the posterior aortic wall in cases 3 and 4 due to the central raphe $\left({ }^{*}\right)$. $L=1$ left; $R$ = right.

(e.g., right coronary cusp in case 1 , noncoronary cusp in cases $3-4)$.

In Table 2 the effective aortic orifice during $15-\mathrm{mm}$ balloon inflation is shown. In cases 1 and 2 a residual free space between balloon and aortic cusps of at least $0.3 \mathrm{~cm}^{2}$ was observed.

On the contrary, in the two cases with a bicuspid valve balloon inflation resulted in an almost com- 
Table 2. Free Residual Aortic Orifice $\left(\mathrm{cm}^{2}\right)$ during Inflation of the 15,19 , and $3 \times 12 \mathrm{~mm}$ Balloons

\begin{tabular}{lcccc}
\hline Balloon Size & Case 1 & Case 2 & Case 3 & Case 4 \\
\hline $15 \mathrm{~mm}$ & 0.53 & 0.31 & 0.07 & 0.02 \\
$19 \mathrm{~mm}$ & 0.30 & 0.17 & 0.12 & 0.01 \\
$3 \times 12 \mathrm{~mm}$ & 0.09 & 0.44 & 0.21 & 0.12 \\
\hline
\end{tabular}

plete occlusion of the aortic orifice. No gross fracture of nodular calcification nor commissural or raphe splitting were observed in any patient at the end of the inflation. A moderate increase in aortic valve area occurred in case 2 , while minimal or no effects were achieved in the remaining cases (Table 1).

Second Dilatation: 19-mm Balloon. The position of the inflated $19-\mathrm{mm}$ balloon for each individual case is shown in Figure 3. Although the balloon still occupied an asymetrical position in the aortic orifice, the displacement of the free edges of the cusps was larger than with the previous balloon, and also involved the most heavily calcified leaflets.

In case 2 the residual aortic valve orifice during inflation was considerably lower than during the previous dilatation (Table 2). After dilatation, a significant increase in aortic valve area was observed in all the patients (Table 1). Fracture of nodular calcifications was noted at visual inspection in case 1 , while in case 2 partial commissural tearing $(=2 \mathrm{~mm})$ was combined with gross fracture of calcifications. Partial tearing of the central calcified raphe of the anterior cusps occurred in cases 3 and 4 (Fig. 3).

Third Dilatation: $3 \times 12-\mathrm{mm}$ Trefoil-shaped Balloon. In cases 3 and 4 the trefoil-shaped balloon occupied an almost central position (Fig. 4) as a result of a further increase in the splitting of the central raphe of the anterior cusp.

On the contrary, in case 2, despite an increase in commissural splitting (from 2 to $5 \mathrm{~mm}$ ) the balloon was still displaced towards the left side of the aortic orifice.

In case 1 the balloon underwent a rotating movement during inflation, so that at the end it occupied the position shown in Figure 4, with one of the three balloons in each of the intercommissural spaces. Multiple cracking noises presumably due to fracture of calcium could be heard with higher inflations.

Despite the larger transverse diameter of the balloon, in cases 2,3 , and 4 , the free residual orifice was paradoxically larger than during the previous dilatation (Table 2), due to the peripheral and central free space created by the trefoil configuration. On the contrary, in case 1 (tricuspid valve without commissural fusion) inflation of the trefoil balloon resulted in a marked reduction of the residual valve orifice because each individual balloon occupied the intercommissural spaces.

In case 1 the increase in cusp motility was associated with full-thickness fracture of heavy nodular calcifications (Fig. 5). In case 2 dilatation resulted in both calcification fracture and partial commissural splitting (Fig. 6). Fracture of the central raphe and separation of the anterior leaflet in two pseudo-hemicusps occurred in cases 3 and 4 (Fig. 7). Bilateral commissural splitting was also noted in case 4. No calcium dislodgement, loosening of valvular tissue, cusp avulsion, or distortion of the aortic ring was observed.

\section{Discussion}

Mechanism of Dilatation. Adult aortic stenosis is characterized by a broad spectrum of underlying pathological changes, ${ }^{17,18}$ which is in contrast to other heart valve diseases where percutaneous valvuloplasty has been applied (pulmonary, mitral stenosis). Therefore, caution should be exercised in the application of our results to other cases with varying anatomical morphology. Nevertheless, it was possible to evaluate the effects of balloon valvuloplasty using semiquantitative methods in specimens with different valve morphology (tricuspid and bicuspid, both with and without commisural fusion) and etiology (degenerative calcification and rheumatic fibrocalcific aortic stenosis).

The importance of the fracture of nodular calcification in decreasing the rigidity of aortic cusps, and of commisural splitting in providing a larger extension of leaflet excursion is apparent and already reported. ${ }^{12,13}$ In our study, accurate evaluation of the distribution of the calcific deposits in the four valves could be provided by computed tomographic scanning. In case 1 (Table 3) no change in volume or density of the valve calcium 

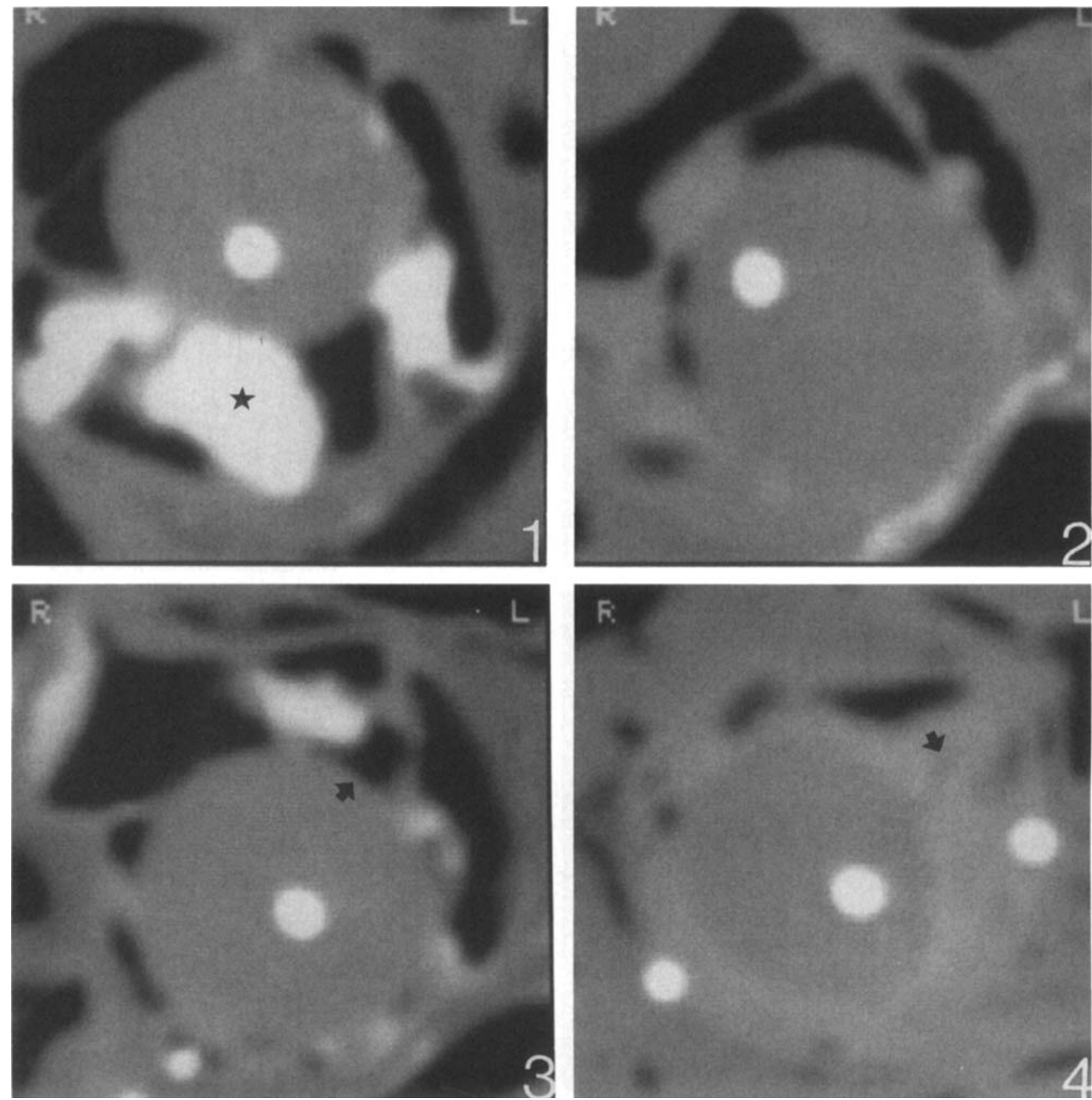

Figure 3. Axial scans of the four specimens during inflation of a $19-\mathrm{mm}$ balloon (enlargement factor: $4 \times$ ). Inflation of the balloon results in an increased stretching of the leaflets in comparison with the previous inflation. The heavily calcified noncoronary cusp (*) is moderately displaced posteriorly in case 1 , the left and right leaflets more widely opened in case 2, while a fracture of the central raphe is shown with arrows in cases 3 and $4 . \mathrm{L}=$ left; $\mathrm{R}=$ right.

deposits could be observed during or after balloon dilatation, suggesting that no redistribution of calcium into adjacent regions occurred, at least in the most heavily calcified valvular portions. Although the complex architecture of the specialized biological tissues of high calcium content (i.e., the bone 
DI MARIO, ET AL.
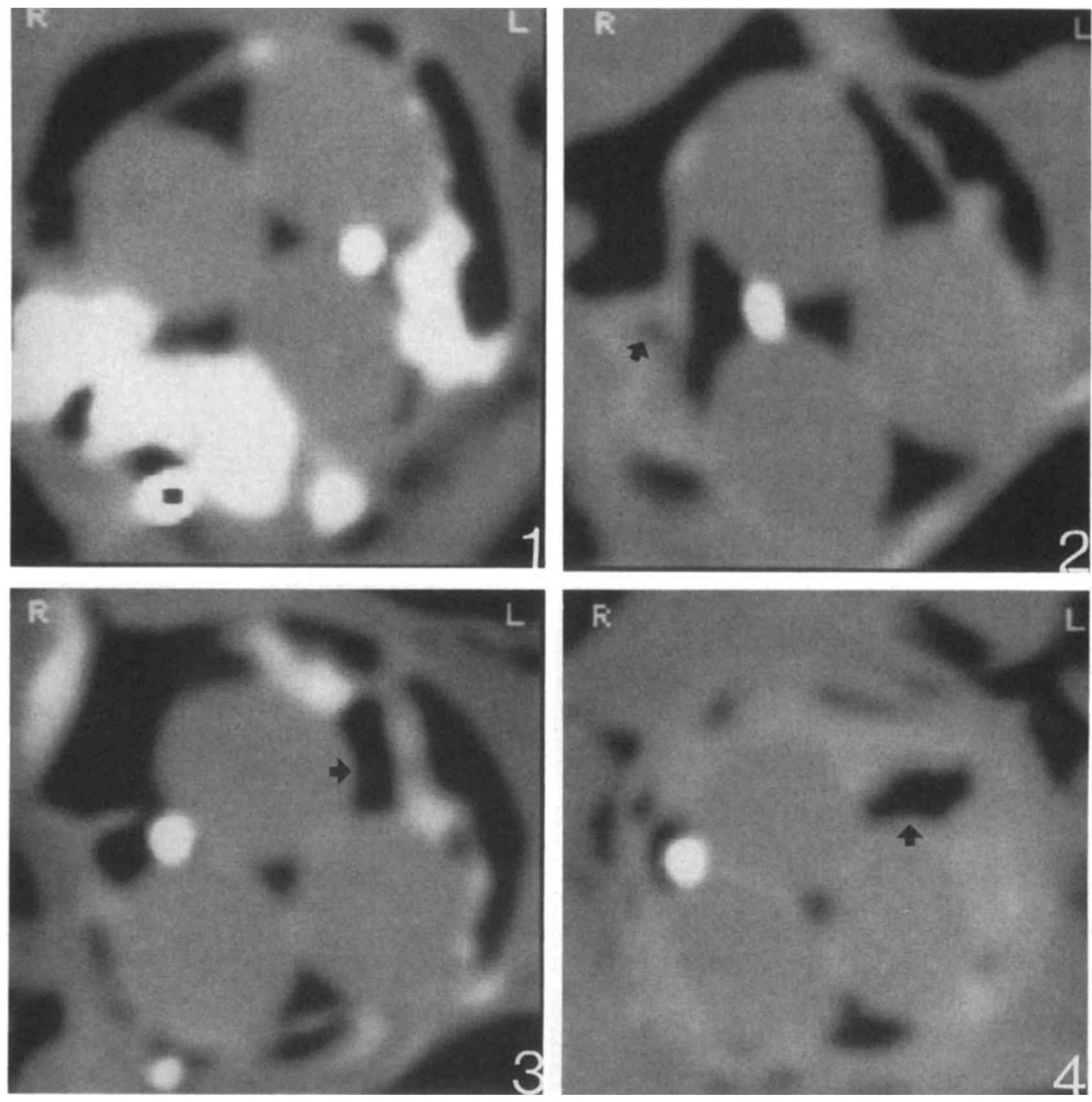

Figure 4: Axial scans of the four specimens during inflation of a $3 \times 12-\mathrm{mm}$ trefoil balloon (enlargement factor: $4 \times$ ). Arrows indicate the partial commissural separation in case 2 , and the almost complete raphe slitting in cases 3 and 4 . $L \times$ left; $R \times$ right.

tissue) provides a vastly superior mechanical resistance in comparison to amorphous degenerative valvular calcifications, increasing mechanical stresses are likely to result in similar effects in both tissues, i.e., no change until the induction of an abrupt fracture once a critical force has been applied.

Formalin preservation denatures valvular fibrous proteins, resulting in stiffening of the valve leaflets and reduction of the elastic properties of 


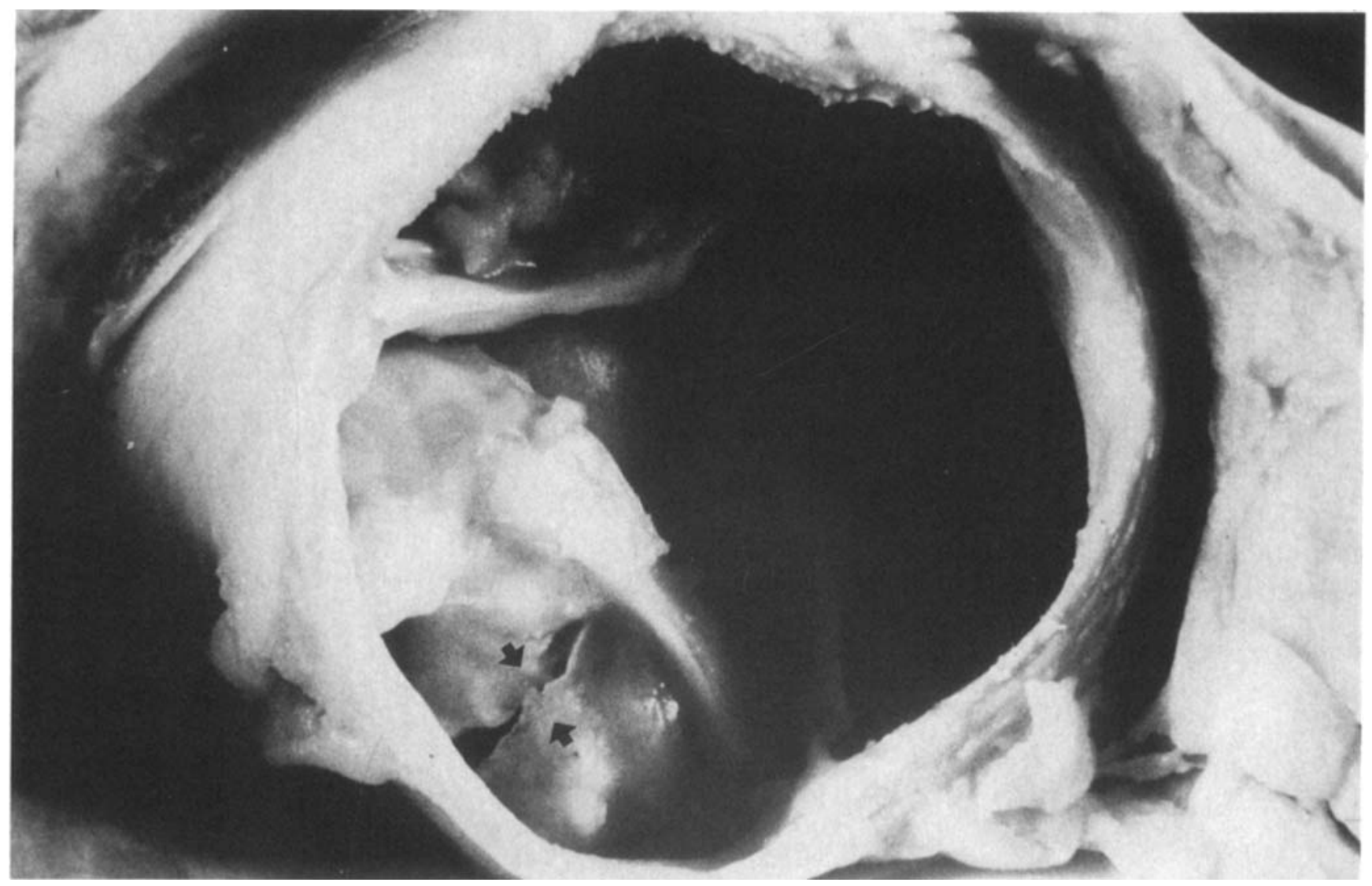

Figure 5. Case 1: a single irregular line of fracture (arrows) can be observed on the heavily calcified noncoronary cusp.

the aortic cusps, while a limited effect on the amorphous calcific tissue can be expected. Therefore, we limited our analysis of the effects of valvuloplasty to macroscopic changes such as splitting of calcified commissures or fractures of calcific vegetations. Nevertheless, other coexisting operative mechanisms (stretching of the fibrous tissue, multiple microfractures of the smallest calcific deposits) may account for the observed increase in valve mobility. However, it should be noted that previous reports ${ }^{12,13}$ compared the effects of balloon dilatation on 27 calcific, stenotic aortic valves dilated after variable periods of fixation in formalin and 12 nonpreserved valves dilated either at postmortem examination or in the operating room and observed no apparent difference in results. The central balloon position across the valve and the lengthy inflation time allowed by the in vitro nature of the procedure presumably explained the larger increase in aortic valve area observed in this study in comparison to the results reported in live patients. ${ }^{2-10}$

Balloon Size. Oversized balloons (10\%-40\% larger than the pulmonary annulus) can achieve better hemodynamic results in pulmonary valvuloplasty. ${ }^{19}$ The main operative mechanism of pulmonary valvuloplasty seems to be commissural splitting, although gross cusp tearing and cusp avulsion have been reported in valves with poorly formed commissures or extensive fibrosis. ${ }^{20} \mathrm{Up}$ to now the fear of producing similar changes in the aortic valve with potentially catastrophic hemodynamic consequences such as major aortic insufficiency, has resulted in a more cautious attitude in aortic balloon dilatation. In calcific aortic stenosis fracture of calcifications may play a more important role than commissural splitting. A direct relationship was observed in our cases between stretching of the free edge of the leaflets and extent of gross calcium fracture. In general, it is expected 


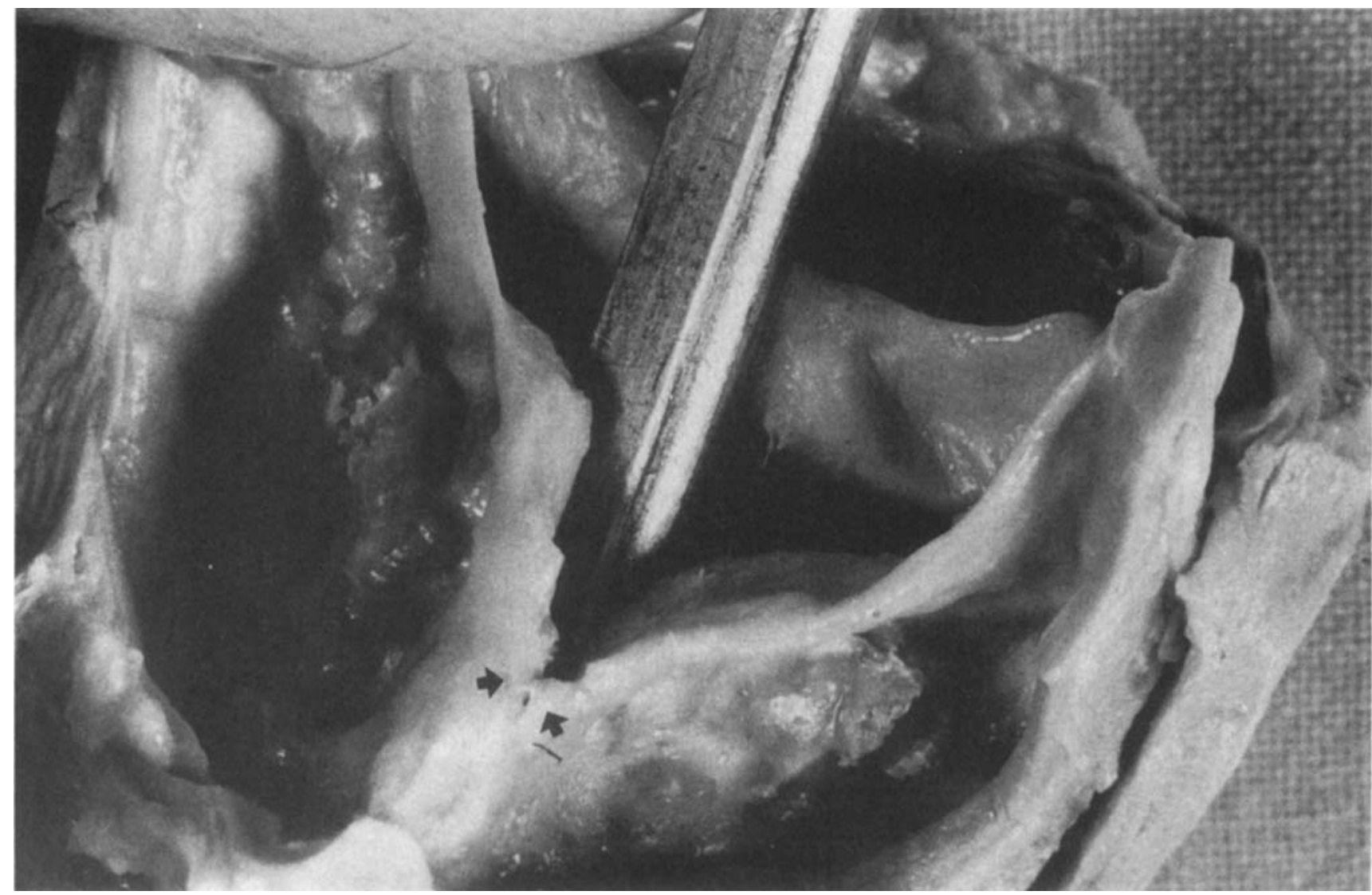

Figure 6. Case 2: gross, irregular fractures of nodular calcifications are apparent on the left coronary (upper) and noncoronary (lower) cusps. Arrows indicate the partial separation in the fused commissure between noncoronary and right coronary cusp.

that the extent of valve stretching is related to the relative dimension of balloon and aortic annulus, but two anatomical variations should be borne in mind: (1) inflation of undersized balloons in comparison to the aortic ring can nevertheless result in significant leaflet stretching when the free edges are shortened because of commissural fusion, as occurred in case 2 with the $15-\mathrm{mm}$ balloon; (2) calcific vegetations, extensively protruding into valve sinuses, can prevent complete apposition of the aortic leaflets against the aortic wall, and reduce the potential advantages of big balloons. This may be an additional explanation of the limited "hemodynamic" improvement achieved in case 1.

Our experimental observations, in accordance with the results of our clinical experience, ${ }^{6}$ point out that the hemodynamic improvement is only moderate, and sometimes minimal or absent, when balloons smaller than $19 \mathrm{~mm}$ are used, and that additional improvement can only be achieved with balloons of larger diameters.

The lack of a linear increase in hemodynamic improvement with balloons of increasing diameter can be explained by: (1) the asymmetrical position occupied by the smallest balloons, so that the effects of inflation are predominantly directed to the less calcified leaflets; (2) the presence of a critical "breaking" point, varying from valve-to-valve, above which stretching of the leaflets results not only in reversible effects on elastic elements, but also in a permanent alteration of valve tissue (macroscopic fracture of nodular calcifications and/or microscopic alterations in the less or noncalcified areas).

Balloon Shape. Trefoil balloons have been developed to avoid complete interruption of blood flow during percutaneous valvuloplasty, and have been effective in allowing continuous blood flow 


\section{COMPUTED TOMOGRAPHY DURING AORTIC VALVULOPLASTY}

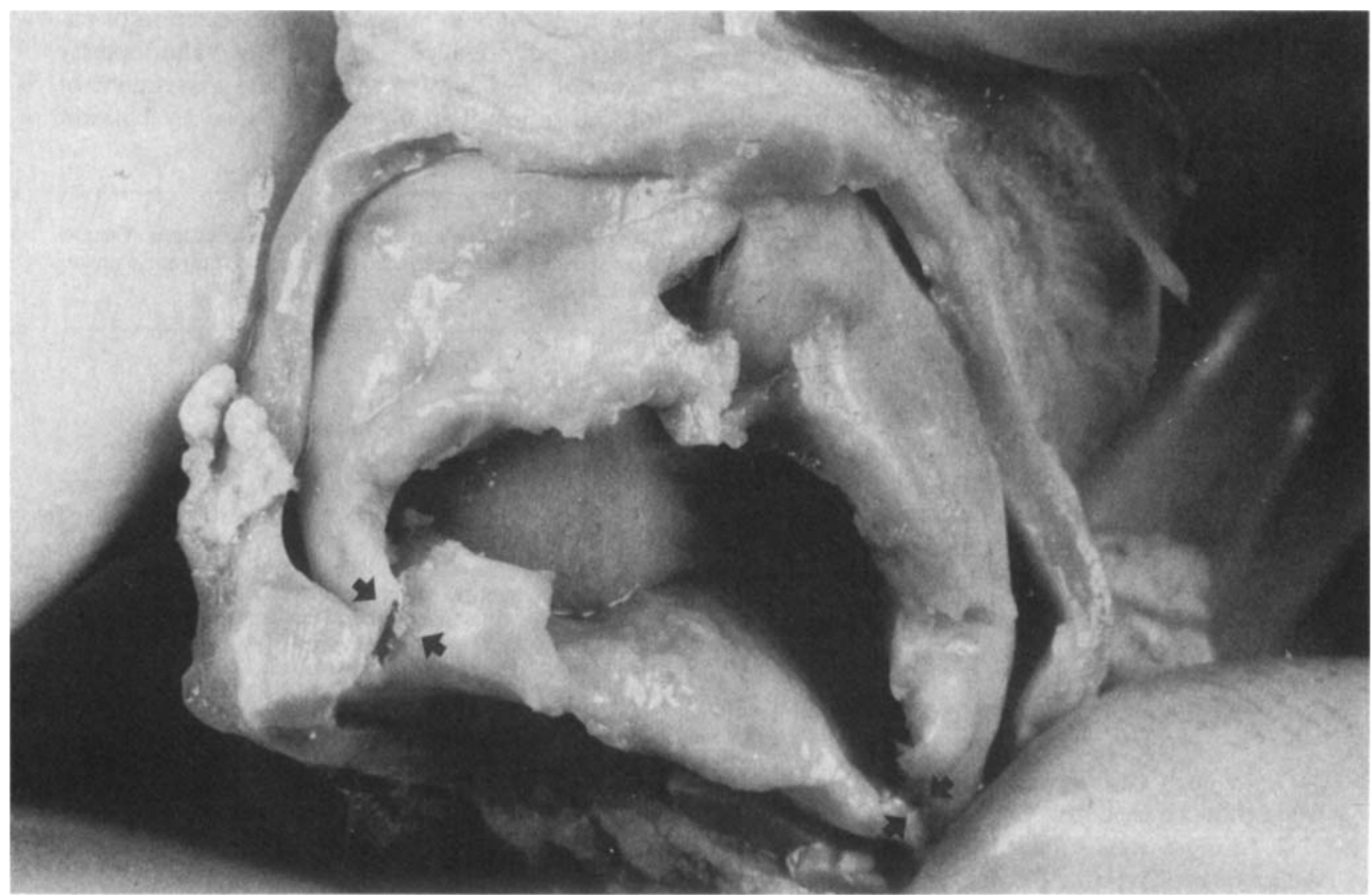

Figure 7. Case 4: shows the larger anterior cusp (upper) of the bicuspid valve where highly irregular tearing of the central raphe can be observed. Partial separation of the fused commissures are indicated with arrows.

during inflation across the aortic valve in dogs, ${ }^{21}$ as well as in pulmonary valvuloplasty in adults, ${ }^{22}$ aortic valvuloplasty in children and young adults, ${ }^{23}$ and in mitral ${ }^{24}$ and aortic ${ }^{25}$ valvuloplasty in adults. Since circular single balloons of $25 \mathrm{~mm}$ were not commercially available at the time of our

Table 3. Case 1: Computed Tomographic Attenuation Values (Hounsfield Units) and Volumes ( $\mathrm{cm}^{3}$ ) of the Calcific Deposits in the Three Aortic Valve Leaflets Before, During and After Each Dilatation

\begin{tabular}{|c|c|c|c|c|c|c|}
\hline & \multicolumn{2}{|c|}{ Non Coronary } & \multicolumn{2}{|c|}{ Left Coronary } & \multicolumn{2}{|c|}{ Right Coronary } \\
\hline & CT Value & Volume & CT Value & Volume & CT Value & Volume \\
\hline Basal & 976 & 0.84 & 832 & 0.24 & 846 & 0.15 \\
\hline During $15 \mathrm{~mm}$ & 915 & 0.90 & 820 & 0.23 & 862 & 0.13 \\
\hline After $15 \mathrm{~mm}$ & 1002 & 0.85 & 838 & 0.23 & 808 & 0.14 \\
\hline During $19 \mathrm{~mm}$ & 947 & 0.91 & 772 & 0.27 & 822 & 0.14 \\
\hline After $19 \mathrm{~mm}$ & 957 & 0.86 & 819 & 0.25 & 846 & 0.13 \\
\hline During $3 \times 12 \mathrm{~mm}$ & 966 & 0.86 & 792 & 0.26 & 829 & 0.13 \\
\hline After $3 \times 12 \mathrm{~mm}$ & 951 & 0.84 & 814 & 0.24 & 812 & 0.13 \\
\hline Mean & 964 & 0.874 & 812 & 0.246 & 832 & 0.136 \\
\hline$\pm \mathrm{SD}$ & 19 & 0.028 & 23 & 0.015 & 20 & 0.008 \\
\hline
\end{tabular}




\section{MARIO, ET AL.}

experimental valvuloplasty, we were unable to compare the effects of a circular and a trefoil balloon of equivalent size. Nevertheless, in the two cases with a bicuspid aortic valve, and in case 2 (tricuspid aortic valve with commissural fusion), we observed a larger free residual area during inflation of the $3 \times 12-\mathrm{mm}$ balloon than during dilatation with the previous $19-\mathrm{mm}$ balloon. On the contrary, in case 1 , an example of the most common pathological findings in aortic stenosis of elderly patients, almost complete occupation of the three intercommissural spaces occurred.

Therefore, the proposed advantage of the trefoil balloon (larger free residual orifice during inflation) seems to be strictly dependant on the valve morphology. Furthermore, the tricuspid configuration of the nonfused, calcific aortic valve in the elderly may be less amenable to effective dilatation by the trefoil balloon.

\section{Conclusions and Clinical Comment}

1. In each case apparent macroscopic effects were induced by aortic valvuloplasty.

2. In most cases substantial enlargement in valvular orifice required dilatation with bigger balloons.

3. The smallest improvement was achieved in the valve where calcification had the largest volume and highest density.

4. No dilatation-related modifications in density and volume of the calcific deposits could be appreciated.

5. The trefoil balloon provided a larger free residual orifice during dilatation of the bicuspid valves and of the valve where commissural fusion was present. On the contrary, a paradoxical, almost complete occlusion was induced in the heavily calcified tricuspid valve without commissural fusion.

In autopsy specimens thin-slice contiguous computed tomographic scanning provides quantitative information on extent of valvular calcification, thorough assessment of balloon-leaflet relationship during inflation, and accurate evaluation of the effects of the dilatation on commissures, leaflets, and nodular calcifications.

Newer "fast" computed tomographic systems may obtain similar information in the clinical set- ting that will help to optimize the selection of patients, individualize the choice of valvuloplasty material, and allow an immediate assessment of the morphological changes induced by balloon aortic valvuloplasty.

Acknowledgments: We are grateful to Gusta Koster, Claudia Sprenger de Rover, and Anja van Huuksloot for their tireless work in compiling this manuscript.

\section{References}

1. Lababidi Z. Aortic balloon valvuloplasty. Am Heart $\mathbf{J}$ 1983; 106:751-752.

2. Cribier A, Saoudi N, Berland J, Savin T, Rocha P, Letac B. Percutaneous transluminal valvuloplasty of acquired aortic stenosis in elderly patients: an alternative to valve replacement? Lancet 1986; 1:63-67.

3. Isner JM, Salem BN, Denoyers MR, Hougen TJ, MacKey WC, Pandian NG, Eichhorn EJ, Konstam MA, Levine HJ. Treatment of calcific aortic stenosis by balloon valvuloplasty. Am J Cardiol 1987; 59:313-317.

4. Jackson G, Thomas S, Monaghan M, Forsyth A, Jewitt D. Inoperable aortic stenosis in the elderly: benefit from percutaneous transluminal valvuloplasty. $\mathrm{Br}$ Med J 1986; 26:81-83.

5. MacKay RG, Safian RD, Lock JE, Diver DJ, Berman AD, Warren SE, Come PC, Baim DS, Mandell VE, Royal HD, Grossman W. Assessment of left ventricular and aortic valve function after aortic balloon valvuloplasty in adult patients with critical aortic stenosis. Circulation 1987; 75:192-203.

6. Di Mario $C$, Beatt $\mathrm{KJ}$, van den Brand $\mathbf{M}$, de Feyter PJ, Essed CE, Serruys PW. Percutaneous balloon dilatation in elderly patients with calcific aortic stenosis. Immediate hemodynamic assessment and short-term clinical followup. Br Heart J 1987; 58:644-652.

7. Dorros G, Lewin RF, King JF, Janke LM. Percutaneous transluminal valvuloplasty in calcific aortic stenosis: the double balloon technique. Cath Cardiovasc Diagn 1987; 13:151-156.

8. Drobinski G, Lechat P, Metzger JP, Lepailleur C, Vacheron A, Grosgogeat Y. Results of percutaneous catheter valvuloplasty for calcified aortic stenosis in the elderly. Eur Heart J 1987; 8:322-328.

9. Berland J, Cribier A, Letac B, Guermonprey JL. Percutaneous aortic valvuloplasty in adults: immediate results of the French Registry. (abstract) Eur Heart J 1987; 8(Suppl 2): 241 .

10. Cribier A, Savin T, Berland J, Rocha P, Mechmecher R, Saoudi N, Behar P, Letac B. Percutaneous balloon valvuloplasty of adult aortic stenosis. Report of 92 cases. J Am Coll Cardiol 1987; 9:381-386.

11. Roberts WC. Good-bye to thoracotomy for cardiac valvulotomy. Am J Cardiol 1987; 59:198-202.

12. McKay RG, Safian RD, Lock JE, Mandell VS, Thure RL, Schnitt SJ, Grossman W. Balloon dilatation of calcific aortic stenosis in elderly patients: postmortem, intra- 


\section{COMPUTED TOMOGRAPHY DURING AORTIC VALVULOPLASTY}

operative, and percutaneous valvuloplasty studies. Circulation 1986; 74:119-125.

13. Safian RD, Mandell VS, Thurer RE, Hutchins GM, Schnitt SS, Grossman W, McKay RG. Postmortem and intraoperative balloon valvuloplasty of calcific aortic stenosis in elderly patients. J Am Coll Cardiol 1987; 9:655660.

14. Vahanian A, Gúerinon J, Michel PL, Slama M, Griveaux M, Acar J. Experimental balloon valvuloplasty of calcified aortic stenosis in the elderly. (abstract) Circulation 1986; 74(Suppl II):II-365.

15. Genant HK, Boyd D. Quantitative bone mineral analysis using dual energy computed tomography. Invest Radiol $1977 ; 12: 545-551$.

16. Zerhouni EA, Boukadoum M, Siddiky MA, Newbold JM, Stone DC, Shirey MP, Sprivey JF, Hesselman CW, Leo FP, Stitix FP, Siegelman SS. A standard phantom for quantitative CT analysis of pulmonary nodules. Radiology $1983 ; 149: 767-73$.

17. Pomerance A. Pathogenesis of aortic stenosis and its relation to age. Br Heart J 1972; 34:569-574.

18. Roberts WC, Perloff JK, Constantino T. Severe valvular aortic stenosis in patients over 65 years of age. Am J Cardiol 1971; 27:497-506.
19. Radtke W, Keane JF, Fellows KE, Lang P, Lock JE. Percutaneous balloon valvotomy of congenital pulmonary stenosis using oversized balloons. J Am Coll Cardiol 1986; 8:909-915

20. Walls JT, Lababidi Z, Curtis JJ, Silver D. Assessment of percutaneous balloon pulmonary and aortic valvuloplasty. J Thorac Cardiovasc Surg 1984; 88:352-356.

21. Meier B, Friedli B, Oberhaensli I, Belenger J, Finci L. Trefoil balloon for percutaneous valvuloplasty. Cath Cardiovasc Diagn 1986; 12:277-281.

22. van der Berg EJM, Niemeyer MG, Plokker TWM, Ernst SMPG, de Korte J. New triple-lumen balloon catheter for percutaneous pulmonary valvuloplasty. Cath Cardiovasc Diagn 1986; 11:352-356.

23. Meier B, Friedli B, Oberhaensli I. Trefoil balloon for aortic valvuloplasty. Br Heart J 1986; 56:292-293.

24. Vahanian A, Michel PL, Slama M, Cormier B, Savier C, Acar J. Percutaneous mitral commissurotomy by a trefoil balloon in adults. (abstract) Circulation 1986; 74(Suppl 2):II-204.

25. Meier B, Friedli B, Segesser L, Belenger J, Finci L, Niederhauser W. Trefoil balloon for valvuloplasty. (abstract) In Meier B, Rutishauser W (eds): Abstracts of PTCA Course IV. Geneva, 1987, p. 20. 